\title{
A Comparative Study in Efficacy of Group Cognitive Behavioral Therapy and Group Hypnotherapy on Depression
}

\author{
Mercede Erfanian' ${ }^{1}$, Azita Keshavarz ${ }^{2}$ \\ ${ }^{1}$ Neuroscience and Psychology Department, Maastricht University, Maastricht, The Netherlands \\ ${ }^{2}$ Psychology Department, Torbat-e-Jam University, Torbat-e-Jam, Iran \\ Email: mercede erfanian@hotmail.com
}

Received 15 April 2014; revised 18 May 2014; accepted 21 June 2014

Copyright (C) 2014 by authors and OALib.

This work is licensed under the Creative Commons Attribution International License (CC BY).

http://creativecommons.org/licenses/by/4.0/

(c) (i) Open Access

\begin{abstract}
Group CBT is an effective treatment for depression, although there is a dearth of research on the treatment of depression using group hypnotherapy. The present study compares the effectiveness of these two therapies on depression. Experimental and convenience sampling were applied with pre and posttest designs. The sample consists of 30 patients with major depression that were split into two groups of 15 subjects. The first group was treated with group hypnotherapy and the second one with group CBT. The data were analyzed by independent t-test. Data shows that depression scores in group hypnotherapy decreased in significance level of $(p<0.01)$, comparing with scores in group CBT and it indicated that a variance is present between the two groups at the pre and posttest in significance level of $(p<0.01)$. In terms of better efficacy, group hypnotherapy is recommended for treatment of depression.
\end{abstract}

\section{Keywords}

Hypnotherapy, Cognitive Behavioral Therapy, Depressive Disorder

Subject Areas: Psychiatry \& Psychology

\section{Introduction}

Major depression disorder is one of the most common psychiatric diagnosis which is characterized by depressed mood, feeling of sadness, low self esteem and lack of interest or pleasure (Anhedonia) in daily activities of any type. Depression is a psychological condition which may emerge from feeling of mild boredom to silence and avoidance of daily activities. Depression is a term that American Psychiatric Association set for mood disorder symptoms (DSM-III in 1980). Depression may affect all aspects of one’s life such as personal, social, occupa- 
tional and even daily activities like eating and sleeping, it can appear in variety of symptoms in different ages. Depression treatments can be divided into two general Pharmaceutical and non-pharmaceutical categories. The efficacy of both treatments was examined in several studies. In severe cases, the use of antidepressants is the best option [1]. These medications have greatly increased in recent decades in terms of quality and quantity so that today no side effects are severe and debilitating [2]. Group Cognitive-ehavioral therapy and in some cases psychoanalysis are also efficient in treatment of depression [3]. In mild cases, doing activities to reduce stress, such as moderate exercising, participation in social activities or other activities that may help one speak and benefit friends company and family members, refraining from drinking alcohol, having a low-fat balanced diet. Group Cognitive-behavioral therapy (CBT) is a form of psychotherapy that helps patients to understand the thoughts and feelings that influence behaviors in the group with exchanging feedbacks. CBT is generally a short-term treatment and focused on helping patients deal with a specific problem. During the treatment process, the individual learns how to identify and change destructive or disturbing thought patterns that have a negative influence on behaviors. So far, the efficacy of CBT has been fully established to treat psychiatric conditions including panic disorder (PD), obsessive-compulsive disorder (OCD) and generalized anxiety disorder (GAD) [4]. One of the necessities of present study is when therapeutic intervention is not done soon enough for clinically depressed patients, this disorder may lead to long-term disability and person can undergo many personal and social dysfunctions [5]. According to above, the present study aims to compare the effectiveness of group hypnotherapy and group CBT in depression disorder.

In a study by Judy and Saedi [6] therapeutic hypnosis was applied as facilitator for acceptance and commitment therapy (ACT) in the treatment of substance abusers that showed positively effectiveness in the process of treatment. Rafi and Hadizadeh [7] investigated the effectiveness of hypnotherapy on students' aggression; the data concluded that hypnotherapy was $27.7 \%$ effective in reduction of aggression in students.

Shakeri et al. [8] compared the efficacy of pharmaceutical and hypnotherapy in treatment of anxiety disorders which was performed among three groups that were randomly selected from different clinics, patients were divided into three control, pharmaceutical and hypnotherapy groups. Hypnosis was more effective in comparison with pharmaceutical treatment to build up self-esteem and reduce the psychological and physical symptoms of depression.

Hypnotherapy which is a branch of psychotherapy, costs a way less than anti-depressant medications. As summarized by Kirsch [9] "Almost nine months after the treatment, the costs of continuing pharmaceutical treatment catch up to the costs of short Hypnotherapy (psychotherapy) sessions and after that, the cumulative costs of medication continue to rise, however hypnotherapy do not" [10].

However, hypnotherapy in the treatment of depression is a relatively new application, with result that controlled research on ways hypnotherapy can be performed in depression treatment which has been under-studied [11]. Alladin and Alibhai [12] evaluated the effectiveness of hypnosis combined with CBT, the first (and the only till now) controlled comparison of hypnosis with another fully understood psychotherapy for depression, meeting the American Psychology Association criteria for a "probably efficacious" treatment for depression. Patients that received CBT produced significantly larger changes in Beck Depression Inventory (BDI), Beck Anxiety Inventory (BAI) and Beck hopelessness Scale (BHS) at 6- to 12-month follow-ups.

\section{Method}

\subsection{Participants}

The study sample population included all patients diagnosed and categorized with depression disorder, whom were referred to A Hypnosis Clinic from April 2012 to June 2013. The sample size consisted of 30 patients between 18 and 45 years old. In this study, we used the Convenience Random Sampling and Sharing statistical method.

\subsection{Materials}

The data were collected through the Self-report, biographies and the Beck Depression Inventory (BDI). In addition, prior to running and collecting the data for this study, participants' consent forms were given to patients included in the survey. 


\subsection{Procedure}

The present study is an experimental study with pretest and post-test designs surveyed by one experimental and one control group. The first group received hypnosis and the second group received CBT. Both groups depression level was measured by Beck Depression Inventory before and after administration of CBT and Hypnotherapy.

\section{Results}

For the descriptive statistical analysis, mean and standard deviation were applied and for the inferential statistical Analysis, to compare experimental and control groups for their baseline and independent t-tests were performed with SPSS software.

Table 1 illustrates the demographic characteristics of participants in Hypnosis group.

Table 2 illustrates the demographic characteristics of participants in CBT group.

Table 3 illustrates mean and standard deviation scores derived from the Beck Depression Inventory (BDI). Pretest $(M=9.48, S D=2.5)$ that declined to their posttest $(M=3.19)$.

Table 4 illustrates mean and standard deviation scores derived from the Beck Depression Inventory (BDI). Pretest $(M=1.47, S D=9.6)$ that declined to their posttest $(M=1.24)$.

Hypothesis: Hypnotic therapy is more effective than CBT in reducing specific, categorical depressive symptoms.

Table 5 provides the results of t-tests, comparing the two types of treatments and their effects on reducing depressive disorder. The data suggest that there is no difference between the pre-test of both groups, however, there is a significant difference between groups' posttest $(a=0.01)$ and Hypnotherapy was more effective than CBT is treatment of depression.

Table 1. Frequency distribution of respondents according to education level, age and marital status in the Hypnosis group.

\begin{tabular}{|c|c|c|c|}
\hline & Variables & Number & Percentage \\
\hline \multirow{4}{*}{ Level of education } & General education diploma & 5 & $33.33 \%$ \\
\hline & College & 3 & $20 \%$ \\
\hline & Bachelor degree & 6 & $40 \%$ \\
\hline & Master degree and above & 1 & $6.66 \%$ \\
\hline \multirow{3}{*}{ Age } & 18 & 6 & $40 \%$ \\
\hline & 26 & 8 & $54.44 \%$ \\
\hline & 34 & 1 & $6.66 \%$ \\
\hline \multirow{2}{*}{ Marital status } & Single & 9 & $60 \%$ \\
\hline & Married & 6 & $40 \%$ \\
\hline
\end{tabular}

Table 2. Frequency distribution of respondents according to education level, age and marital status in the CBT group.

\begin{tabular}{|c|c|c|c|}
\hline & Variables & Number & Percentage \\
\hline \multirow{4}{*}{ Level of education } & General education diploma & 4 & $26.66 \%$ \\
\hline & College & 5 & $33.33 \%$ \\
\hline & Bachelor degree & 5 & $33.33 \%$ \\
\hline & Master degree and above & 1 & $6.66 \%$ \\
\hline \multirow{3}{*}{ Age } & 18 & 5 & $33.33 \%$ \\
\hline & 26 & 9 & $60 \%$ \\
\hline & 34 & 1 & $6.66 \%$ \\
\hline \multirow{2}{*}{ Marital status } & Single & 8 & $53.33 \%$ \\
\hline & Married & 7 & $46.66 \%$ \\
\hline
\end{tabular}


Table 3. Means and standard deviations of pre-test and post-test scores of the subjects on the Beck Depression Inventory (BDI) in hypnosis group.

\begin{tabular}{cccc}
\hline Variables & Groups & Mean & Standard deviation \\
Depression & Pretest & 48.9 & 5.2 \\
& Posttest & 19.3 & 6.1 \\
\hline
\end{tabular}

Table 4. Mean and standard deviation scores from pre-test and post-test results found applying the Beck Depression Inventory (BDI) in CBT group.

\begin{tabular}{cccc}
\hline Variables & Groups & Mean & Standard deviation \\
\hline \multirow{2}{*}{ Depression } & Pretest & 47.1 & 6.9 \\
& Posttest & 24.1 & 6.4 \\
\hline
\end{tabular}

Table 5. Results of independent t-test to compare the scores of hypnotherapy and CBT at Beck Depression Inventory (BDI).

\begin{tabular}{cccccccc}
\hline Significance level N.S & Degrees of freedom & $\mathrm{T}$ & $\mathrm{SD}$ & Mean & Treatment & Groups & Variable \\
\hline 0.417 & 28 & 9.4 & 5.2 & 48.9 & Hypnosis & Pretest & Depression \\
& & & 6.1 & 47.1 & CBT & & Posttest \\
0.01 & \multirow{2}{*}{28} & 11.21 & 6.9 & 19.03 & Hypnosis & CBT & \\
\end{tabular}

\section{Discussion}

As a result, these findings indicate that a variance is present between the two groups in significance at the pretest and posttest $(p<0.01)$ levels. It has also outlined some of the positive changes that have helped professionalise this modality. Having demonstrated the efficacy, value and quality of contemporary group hypnotherapy it is important that group hypnotherapy continue to be part on private health insurance.

Data showed that depression scores in group hypnotherapy decrease $(p<0.01)$ in significance level in compare to scores in group cognitive behavioral therapy. Likewise, this study has demonstrated the clinical efficacy clinical group hypnotherapy in depression and its benefits comparing with group cognitive behavioral therapy (CBT) as practiced which was more significant in treating depression based on our data.

\section{References}

[1] Baghai, T.C., Moller, H.J. and Rupprecht, R. (2006) Recent Progress in Pharmacological and Non-Pharmacological Treatment Options of Major Depression. Current Pharmaceutical Design, 12, 503-515. http://dx.doi.org/10.2174/138161206775474422

[2] Morris, J.T. and Beck, A. (1974) The Efficacy of Antidepressant Drugs: A Review of Research (1958 to 1972 ). Archives of General Psychiatry, 30, 667-674. http://dx.doi.org/10.1001/archpsyc.1974.01760110083010

[3] Sidney, J.B. (2013) Contributions of Psychoanalysis to the Understanding and Treatment of Depression. The Journal of American Psychoanalysis Association, 46, 723-752.

[4] Yatham, L.N., Kennedy, S.H., O’Donovan, C., Parikh, S.V., MacQueen, G., McIntyre, R.S., Sharma, V., Beaulieu, S. and CANMAT Guidelines Group (2006) Canadian Network for Mood and Anxiety Treatments (CANMAT) Guidelines for the Management of Patients with Bipolar Disorder: Update 2007. Bipolar Disorders Journal, 8, 721-739. http://dx.doi.org/10.1111/j.1399-5618.2006.00432.x

[5] Wells, A. (1995) Meta-Cognition and Worry: A Cognitive Model of Generalized Anxiety Disorder. Behavioral and Cognitive Psychotherapy Journal, 23, 301-320. http://dx.doi.org/10.1017/S1352465800015897

[6] Saeedi, M. and Judy, M. (2012) Application Acceptance and Commitment Therapy in the Treatment of Substance Dependence Disorders Using Hypnosis. Paper Presented at the 1st International Conference on Hypnosis and Related Sciences, Iran.

[7] Rafii, T. and Hadizadeh, R. (2012) Hypnotherapy Effect on Students’ Aggression. Paper Presented at the 1st Interna- 
tional Conference on Hypnosis and Related Sciences, Iran.

[8] Shakeri, H., Varkany, E., Saberi, M. and Ghavami, B. (2012) Comparison of Drug Therapy and Hypnosis in the Treatment of Anxiety Disorders. Paper Presented at the 1st International Conference on Hypnosis and Related Sciences, Iran.

[9] Kirsch, I. (2010) The Emperor’s New Drugs: Exploding the Antidepressant Myth. Random House, London.

[10] Dobson, K.S., Hollon, S.D., Dimidjian, S., Schmaling, K., Kohlenburg, R., Gallop, R., Rizvi, S., Gollan, J., Dunner, D. and Jacobson, N. (2008) Randomized Trial of Behavioral Activation, Cognitive Therapy and Anti-Depressant Medication in the Prevention of Relapse and Recurrence in Major Depression. Journal of Consulting and Clinical Psychology, 76, 468-477. http://dx.doi.org/10.1037/0022-006X.76.3.468

[11] Yapko, M.D. (2012) Treating Depression with Hypnosis: Integrating Cognitive Behavioral and Strategic Approaches.

[12] Alladin, A. and Alibhai, A. (2007) Cognitive Hypnotherapy for Depression: An Empirical Investigation. International Journal of Clinical and Experimental Hypnosis, 55, 147-166. http://dx.doi.org/10.1080/00207140601177897 